\title{
Subjective organization following constant input order in multitrial free recall ${ }^{1}$
}

WILLIAM P. WALLACE ${ }^{2}$ and GARYW. NAPPE, University of Nevada, Reno, Nev. 89507

The present experiments were designed to assess the influence of consistent contiguous relations among list members on the development of subjective organization. One major source of contiguity experiences is provided by $E$ 's arrangement of items during study trials. In the present experiments, recall following constant and varied input order was compared. Constant input order assures that the nominal input contiguity relations are consistent across trials. The results indicated that constant-input-order groups were superior to varied-input-order groups in terms of correct responses, subjective-organization scores, and input-order/output-order consistency scores.

Generally, studies of subjective organization (the empirical phenomenon of recall-order consistency) have involved free-recall tasks with preexperimental and laboratory-produced conceptual relations among items minimized. However, the fact that organization can be demonstrated in the absence of obvious input (study trials) relations does not mean that input components have no role in the development of organization. Wallace (1970) has proposed that contiguity relations that exist among list members during input and output (recall trials) phases of a multitrial free-recall procedure lead to the development of associations that influence specific recall orders. An experiment investigating the role of consistent output-contiguity experiences reported that procedures presumed to reduce the opportunity for strengthening associations during output interfered with the development of subjective organization (Wallace, 1969). The purpose of the present experiments was to examine the influence of consistent input-contiguity experiences on the development of consistent recall order (referred to hereafter as subjective organization).

\section{EXPERIMENT 1}

Constant input order, compared to varied input order, guarantees that the contiguity relations that result from the

Fig. 1. Mean number of words recalled across trials as a function of exposure rate and presentation order. nominal input order will be consistent across trials. If consistent contiguous experiences lead to associations that influence the phenomenon of subjective organization, then constant input order ought to facilitate the development of organization in recall.

\section{Materials}

A list of 16 words was presented for 10 alternating study and test trials. The list consisted of the 15 unrelated words from Deese's (1959) List 18, plus the inappropriate label.

\section{Procedure}

The experiment may be thought of as a 2 by 2 factorial combination of two variables: The list was presented in a constant order (C) on all trials or in a different random order (R) across trials, and the exposure rate during study and test trials was $1 \mathrm{sec}(\mathrm{F})$ or $2 \mathrm{sec}$ (S) (it was reasoned that rapid exposure rates would minimize rehearsal alterations from the nominal input order). The 16 -word list was presented in a different random order to the $\mathbf{R}$ groups on each of the first five trials. Trials 6 through 10 involved a repetition of the first five random input orders.

There were two constant-order subgroups at each exposure rate. The 16-word list was arranged in a random order, and Ss in the $\mathrm{C}$ groups viewed the same input order on all 10 study trials. One input order for constant-order subgroups $\left(C_{1}\right)$ was identical to the order the $R$ groups viewed on Trials 1 and 6 , and the input order for the other constant-order subgroups $\left(\mathrm{C}_{2}\right)$ was identical to the order used on Trials 5 and 10 for the R groups. Following each study trial, Ss were given a paced oral recall test (cf. Ekstrand \& Underwood, 1963).

\section{Subjects}

A total of 120 introductory psychology students participated in the experiment. Twenty Ss were assigned randomly to each of the two $R$ groups, and 40 Ss were assigned randomly to each of the two main $\mathrm{C}$ groups (20 Ss in each subgroup).

Results

Recall. The mean numbers of items correctly recalled are presented in Fig. 1. The $\mathrm{C}$ subgroups are presented separately. In order to check the comparability of the C subgroups, they were compared on total correct responses. The presentation order for $\mathrm{C}_{2}$ subgroups was associated with higher recall than was the $\mathrm{C}_{1}$ order $[\mathrm{F}(1,76)=3.98, \quad \mathrm{p}<.05]$. The major analysis revealed that recall was significantly higher following 2-sec exposure rates, compared to 1 -sec rates $[F(1,114)=108.93, \quad p<.01]$, constant input order led to higher recall than did varied input order $\left(C_{1}+C_{2}\right.$ vs $\left.R\right)$ $[F(1,114)=24.46, p<.01]$, and $C_{2}$ input order was associated with higher recall than was the $C_{1}$ order $[F(1,114)=4.15$, $\mathrm{p}<.05]$. Recall improved over trials $[F(9,1026)=313.99, p<.01]$, and there

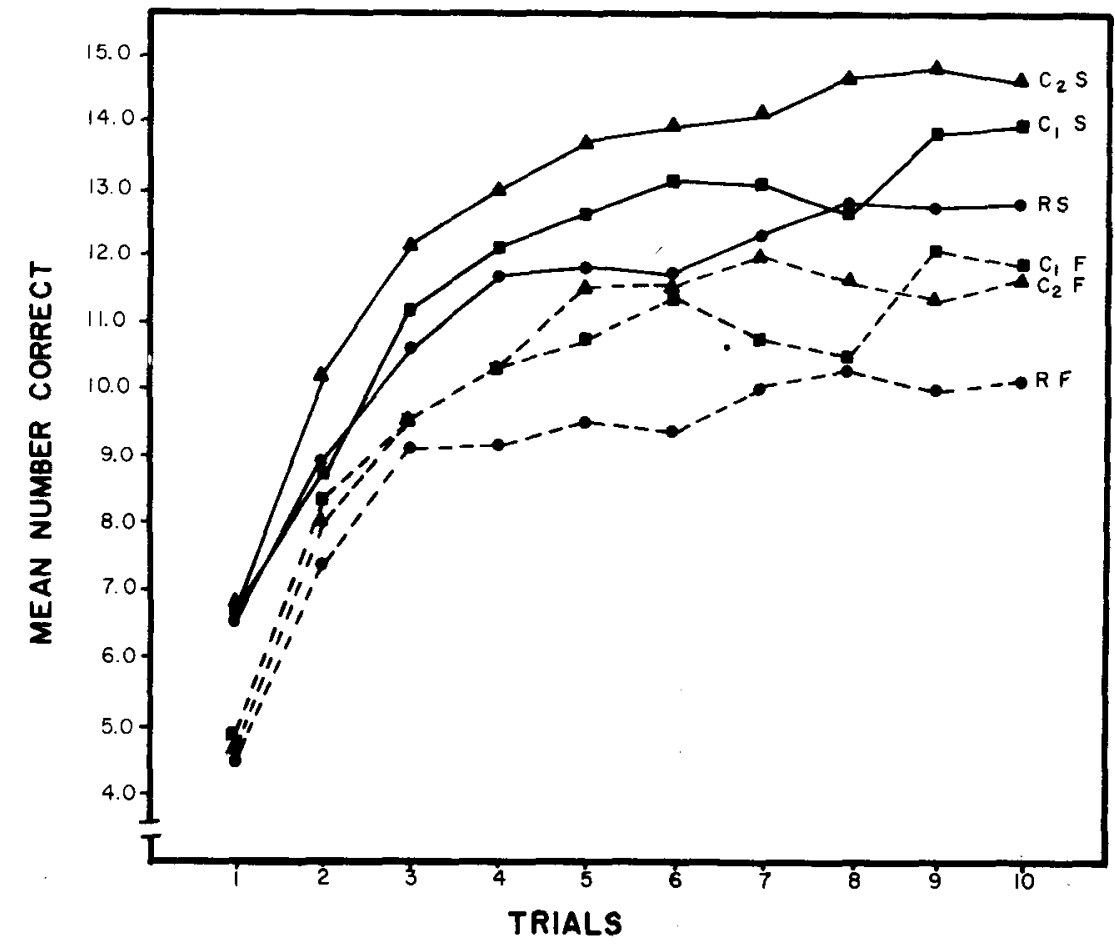


was a significant Trials by Input Order interaction $[\mathrm{F}(18,1026)=3.93, \mathrm{p}<.01]$. The $\mathrm{R}$ groups appeared to reach an asymptotic level of performance earlier in learning than did the $\mathrm{C}$ groups.

Subjective organization. Subjective organization was assessed by Bousfield \& Bousfield's (1966) measure of intertrial repetition (ITR). A comparison of the constant-input-order subgroups in terms of the total observed (O) minus the expected (E) ITRs was not significant $[F(1,76)=2.70]$. Since the $C$ subgroups did not differ significantly, they were combined.

The mean ITR scores are presented in Fig. 2. All effects were significant in the analysis of variance. The organization scores were higher for 2-sec exposure rates, compared to 1 -sec rates $[F(1,116)=27.89$, $p<.01]$; they were higher following constant input order, compared to varied input order $[F(1,116)=45.68, p<.01]$; and they differed as a function of trial pairs $[F(8,928)=23.39, p<.01]$. There was a significant interaction as the difference between constant and varied input order with the 2 -sec exposure rate was substantially greater than it was following a $1-\mathrm{sec}$ exposure rate $[F(1,116)=5.69, p<.05]$. The significant interactions across trial pairs resulted mainly from the performance of the CS group, which displayed organization scores that increased over trial pairs and were superior to the other groups [Trial Pairs by Exposure Rate: $F(8,928)=10.57, \mathrm{p}<.01$; Trial Pairs by Input Order: $F(8,928)=5.95, p<.01$; and Trial Pairs by Exposure Rate by Input Order: $\mathrm{F}(8,928)=2.56, \mathrm{p}<.05]$.

Input-output consistency. It was argued earlier that constant input order should facilitate the development of subjective organization, because repetitions of specific input-contiguity experiences would lead to the formation of associations that determine output order. Thus, it seems reasonable to expect some agreement between input orders and output orders for the $\mathrm{C}$ groups. The ITR measure used to assess subjective organization was applied to measure the agreement between recall orders and corresponding study orders. It should be noted that organization scores and input-output consistency scores may not be independent.

An O(ITR)-E(ITR) score, based upon the input order and output order for each trial, was computed for each S. Since the C subgroups did not differ significantly on these scores $[F(1,76)=1.86]$, the subgroups were combined.

Fig. 3. Mean input-order/output-order consistency scores across trials.

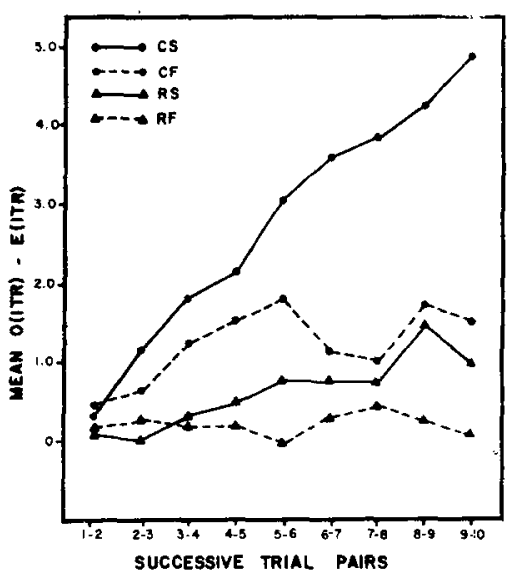

Fig. 2. Mean subjective organization scores across successive trial pairs.

The mean ITR scores for input-output consistency are presented in Fig. 3. An analysis of variance comparing input-output consistency scores revealed that all effects were significant. The ITR scores were higher for 2 -sec exposure rates, compared to $1-\mathrm{sec}$ rates $[\mathrm{F}(1,116)=20.04$, $p<.01]$; they were higher following constant input order, compared to varied input order $[F(1,116)=29.91, p<.01]$; and they differed as a function of trials $[F(9,1044)=28.96, p<.01]$. There was a significant interaction as the difference between constant and varied input order with the 2-sec exposure rate was substantially greater than it was following a $1-\sec$ rate $[F(1,116)=6.98, p<.01]$. The significant interactions with trials resulted mainly from the performance of the CS group, which displayed input-output consistency scores that increased across trials and were superior to the other groups [Trials by Exposure Rate: $\mathrm{F}(9,1044)=14.20, \quad p<.01 ;$ Trials by Input Order: $F(9,1044)=19.64, p<.01$; and Trials by Exposure Rate by Input Order: $F(9,1044)=9.06, p<.01]$.

\section{EXPERIMENT 2}

Experiment 2 was undertaken in an attempt to replicate Experiment 1, with variations in procedures and materials. Method

The materials were taken from Deese's List 9. The words were presented in a constant order (C) on all study trials or in a different random order ( $R$ ) on each study trial. The words were presented at a $4-\mathrm{sec}$ rate during study trials, and approximately $60 \mathrm{sec}$ were allowed for written recall on each test trial. There were eight test trials and six study trials, with the sequence of study (S) and test (T) trials as follows: S T S T S T T S T S T S T T. The third and fourth test trials and the seventh and eighth test trials were given without an interspersed study trial.

A total of 40 introductory-psychology students participated in this experiment. Twenty Ss were assigned at random to Group C, and 20 Ss were assigned at random to Group R.

\section{Results}

Recall. The means and standard deviations for correct recall are presented in the first two columns of Table 1. Group C recalled significantly more words than did Group $R \quad[F(1,38)=8.12$, $\mathrm{p}<.01]$. The number of words correctly recalled showed a general increase across trials $[F(7,266)=131.32, p<.01]$. The

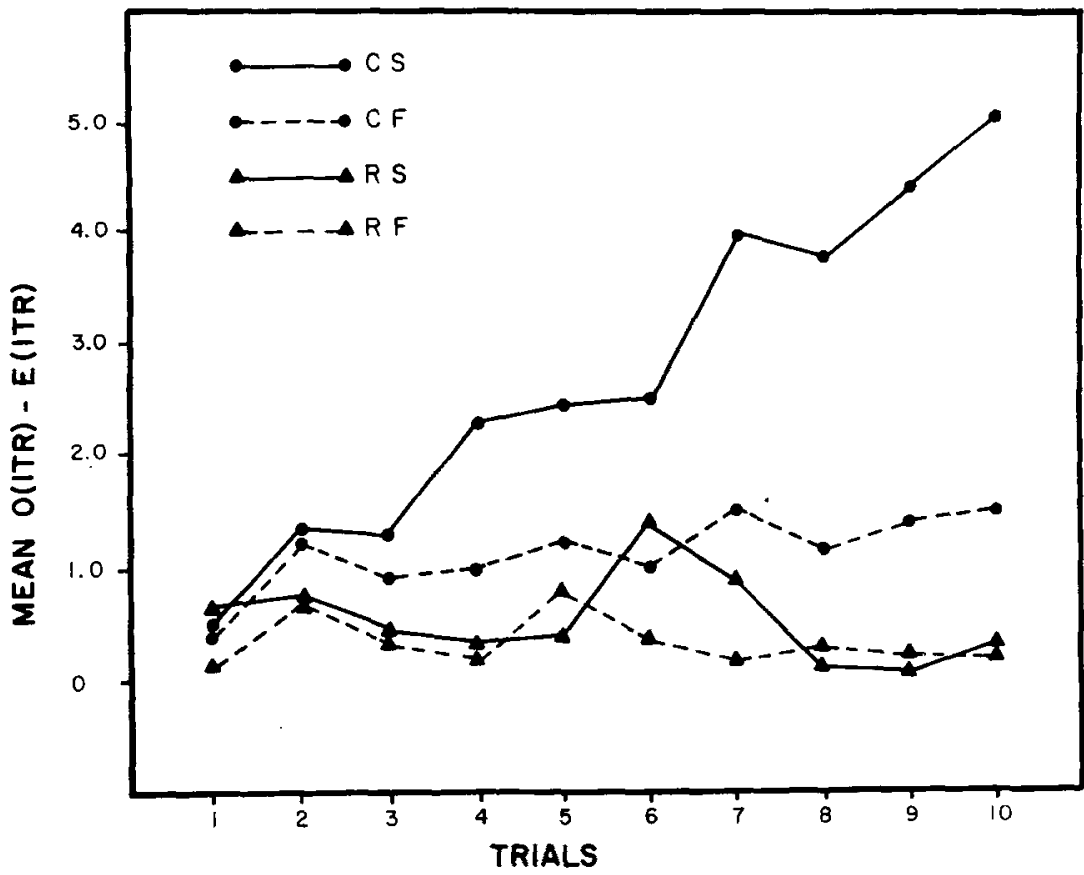


Table 1

Means $(\overline{\mathrm{X}})$ and Standard Deviations (SD) for Critical Response Measures Averaged Across Trials (Experiment 2)

\begin{tabular}{|c|c|c|c|c|c|c|}
\hline & \multicolumn{2}{|c|}{ Number Correct } & \multicolumn{2}{|c|}{$\begin{array}{c}\text { Subjective } \\
\text { Organization }\end{array}$} & \multicolumn{2}{|c|}{$\begin{array}{c}\text { Input-Output } \\
\text { Consistency }\end{array}$} \\
\hline & $\bar{X}$ & SD & $\overline{\mathbf{X}}$ & SD & $\overline{\mathrm{X}}$ & $\mathrm{SD}$ \\
\hline Group C & 12.66 & 1.52 & 2.66 & 2.38 & 3.32 & 3.02 \\
\hline Group R & 11.14 & 1.84 & 1.10 & 1.20 & .35 & .48 \\
\hline
\end{tabular}

interaction, which was significant in Experiment 1, was not significant in this experiment $[F(7,266)=1.55]$. There was a decline in number of correct responses across the test trials that were not separated by a study trial, compared to the immediately preceding test trials (the mean number correct on Trial $3+$ Trial $7-$ Trial $4-$ Trial $8=+.80$ ).

Subjective organization. The ITR measure discussed in Experiment 1 was used to assess the levels of organization. The means and standard deviations for ITR scores are presented in Columns 3 and 4 of Table 1. Organization scores were higher for Group $\mathrm{C}$ than they were for Group $\mathrm{R}$ $[F(1,38)=6.86, p<.05]$, and they increased over trial pairs $[F(6,228)=20.60, p<.01]$. The gains in organization scores across trial pairs tended to be greater in Condition $\mathrm{C}$, compared to Condition $\mathrm{R}$, resulting in a significant interaction $[F(6,228)=2.99, \quad p<.01]$. Contrary to results involving correct recall, organization scores increased, rather than decreased, across test-trial pairs that were not separated by a study trial, compared to scores on immediately preceding test-trial pairs (the mean organization score on Trial Pair 2-3 + Trial Pair 6-7 - Trial Pair 3-4 Trial Pair $7.8=-1.19$ ).

Input-output consistency. The means and standard deviations for ITR scores based on input-order/output-order consistency are presented in Columns 5 and 6 of Table 1 . Consistency scores were higher for Group C, compared to Group R $[F(1,38)=18.82, \quad p<.01]$, and they increased over trials $[F(7,266)=10.57$, $\mathrm{p}<.01]$. There was little change in consistency scores across trials for Group R, whereas there was a substantial increase for Group $C$, resulting in a significant interaction $[F(7,266)=11.14$, $\mathrm{p}<.01]$. Compared to the consistency scores on immediately preceding test trials, there was little change across test trials that were not separated by a study trial. (The mean consistency scores on Trial $3+$ Trial $7-$ Trial $4-$ Trial $8=-.15$ ).

$$
\text { DISCUSSION }
$$

It has been suggested here that the phenomenon of subjective organization reflects the operation of associative processes. Contiguity relations among "unrelated" words that exist during study trials provides one source for the development of associations. Constant input order was presumed to increase the consistency of specific input-contiguity experiences. Correct recall, subjective organization, and input-order/output-order consistency scores were all enhanced following constant input order. Variations in list materials and in presentation procedures did not alter these basic findings.

The present data are discrepant with some of the existing literature on free recall that report no difference between constant and varied input order (Stimmel \& Stimmel, 1967; Waugh, 1961). However, the data are consistent with other reports that indicate constant input order facilitates free recall and organization (Jung \& Skeebo, 1967; Lachman \& Laughery, 1968; Mandler \& Dean, 1969). In the present experiments, there was substantial agreement between input order and output order for the $\mathrm{C}$ groups.
Recently, Mandler \& Dean (1969) have demonstrated similar results with further variations in presentation procedures. Serial organization was adopted by Ss whenever possible in the Mandler and Dean study, and they argued that seriation is a preferred method of organizing materials. The empirical phenomenon of serial organization demonstrated in the present experiments was interpreted as reflecting the formation of sequential associations during input.

\section{REFERENCES}

BOUSFIELD, A. K., \& BOUSFIELD, W. A. Measurement of clustering and of sequential constancies in repeated free recall. Psychological Reports, 1966, 19, 935-942.

DEESE, J. Influence of inter-item associative strength upon immediate free recall. Psychological Reports, 1959, 5, 305-312.

EKSTRAND, B., \& UNDERWOOD, B. J. Paced versus unpaced recall in free learning. Journal of Verbal Learning \& Verbal Behavior, 1963. $22,288-290$

JUNG, J., \& SKEEBO, S. Multi-trial free recall as a function of constant vs. varied input orders and list length. Canadian Journal of Psychology, 1967, 21, 329-336.

LACHMAN, R., \& LAUGHERY, K. R. Is a test trial a training trial in free recall learning? Journal of Experimental Psychology, 1968, 76, 40-50.

MANDLER, G., \& DEAN, P. J. Seriation: The development of serial order in free recall. Journal of Experimental Psychology, 1969, 81, 207-215.

STIMMEL, D. T., \& STIMMEL, N. S. Free recall as a function of intralist similarity and order of presentation constraints. Psychological Reports, 1967, 21, 541-544.

WALLACE, W. P. Influence of test trials on the development of subjective organization in free recall. Journal of Experimental Psychology, $1969,81,527.535$

WALLACE, W. P. The consistency of emission order in free recall. Journal of Verbal Learning \& Verbal Behavior, 1970, in press.

WAUGH, N. C. Free versus serial recall. Joumal of Experimental Psychology, 1961, 62, 496-502.

\section{NOTES}

1. The research reported here was supported by Grant GB8605 from the National Science Foundation.

2. Currently visiting The Institute of Human Learning, University of California, Berkeley, Calif. 94720 . 